\title{
Synthesis, Properties and Redox Behavior of Ene-Diyne Scaffolds Bearing 1- and 2-Azulenyl groups at the Periphery
}

\author{
Taku Shoji, ${ }^{[\mathrm{a}]}$ Erika Shimomura, ${ }^{[\mathrm{a}]}$ Mitsuhisa Maruyama, ${ }^{[\mathrm{a}]}$ Shunji Ito, ${ }^{[\mathrm{b}]}$ Tetsuo Okujima, ${ }^{[\mathrm{c}]}$ and \\ Noboru Morita ${ }^{[\mathrm{d}]}$
}

Dedicated to Professor Klaus Hafner on the occasion of his 85th birthday

Keywords: Azulene / Ene-diyne / $\pi$-Conjugate system /Coupling reaction / Redox chemistry /

The ene-diyne systems possessing 1-and 2-azulenyl groups at the
periphery, were prepared by the palladium-catalyzed cross-coupling
reaction of 1 - and 2 -ethynylazulenes
$\begin{array}{lr}\text { 9-dibromomethylene-9H-fluorene } \\ \text { 9,10-bis(dibromomethylene)-9,10-dihydroanthracene }\end{array}$
$\begin{aligned} & \text { 2-iodoazulene } \\ & \text { 9,10-bis(diethynylmethylene)-9,10-dihydroanthracene under } \\ & \text { Sonogashira-Hagihara conditions. }\end{aligned}$

[a] Department of Chemistry, Faculty School of Science, Shinshu University, Matsumoto 390-8621, Japan Fax: +81-263-37-2476 E-mail: tshoji@shinshu-u.ac.jp

[b] Graduate School of Science and Technology, Hirosaki University, Hirosaki 036-8561, Japan

[c] Department of Chemistry and Biology, Graduate School of Science and Engineering, Ehime University, Matsuyama 790-8577, Japan

[d] Department of Chemistry, Graduate School of Science, Tohoku University, Sendai 980-8578, Japan

Supporting information for this article is available on the WWW under http://www.eurjoc.org/ or from the author.

\section{Introduction}

The ene-diyne unit is a molecular scaffold designed for molecular architectures that contain one- and two-dimensional carbon networks. ${ }^{[1]}$ Interest in conjugated ene-diynes has been growing because of their wide range of applications, for example, to molecular wires, non-linear optics (NLOs) and molecular switches. Therefore, a variety of ene-diyne compounds have been prepared and their properties (e.g., reactivity ${ }^{[2]}$ and fluorescence ${ }^{[3]}$ ) have been extensively studied. An ability to undergo multi-electron reduction of the ene-diyne system owing to their strong electron-accepting nature has also been revealed by electrochemical studies under cyclic voltammetric conditions, so far. $^{[4]}$

Azulene $\left(\mathrm{C}_{10} \mathrm{H}_{8}\right)$ has attracted the interest of many research groups owing to its unusual properties as well as its beautiful blue color. ${ }^{[5]}$ Previously, we reported the synthesis of azulene-substituted ene-diyne systems substituted by 6-position, which exhibit multi-step reduction waves on cyclic voltammetry $(\mathrm{CV})$ and differential pulse voltammetry (DPV) (Figure 1). ${ }^{[6]}$ Moreover, we have also revealed that the ene-diyne systems are new examples of violene-cyanine $(\mathrm{V}-\mathrm{C})$ hybrids ${ }^{[7]}$ with a strong absorption in the near-infrared region in the electrochemically ith
The redox behavior of the ene-diyne compounds was examined by cyclic voltammetry (CV) and differential pulse voltammetry (DPV). Moreover, a significant color change of the ene-diyne derivatives was observed by visible spectroscopy under the electrochemical reduction conditions. 
Methyl 3-ethynyl-7-isopropylazulene-1-carboxylate (1) ${ }^{[10]}$ and 2-ethynylazulene $(7)^{[8 a, 11]}$ were prepared by Sonogashira-Hagihara reactions. Preparation of the corresponding ene-diyne derivatives $\mathbf{3}$, 5, 8 and 11 was accomplished by a simple one-pot reaction involving repeated Pd-catalyzed alkynylation of the corresponding ethynylazulenes (1 and 7) with 9-dibromomethylene- $9 H$-fluorene (2) and 9,10-bis(dibromomethylene)-9,10-dihydroanthracene (4) or 2-iodoazulene

with 9,10-bis(diethynylmethylene)-9,10-dihydroanthracene (10) under Sonogashira-Hagihara conditions.

The cross-coupling reaction of 1-ethynylazulene (1) with 2 using $\mathrm{Pd}\left(\mathrm{PPh}_{3}\right)_{4}$ as a catalyst and subsequent chromatographic purification on silica gel afforded the desired product 3 in $89 \%$ yield (Scheme 1). Likewise, the reaction of $\mathbf{1}$ with $\mathbf{4}$ afforded compound $\mathbf{5}$ in $74 \%$ yield (Scheme 1). These reactions proceeded under mild conditions, although the electron-withdrawing group, the methoxycarbonyl group, is substituted on the azulene ring. The high reactivity of acetylene moiety of $\mathbf{1}$ can be ascribed to the electron-donating properties of the azulene ring at the 1-position.

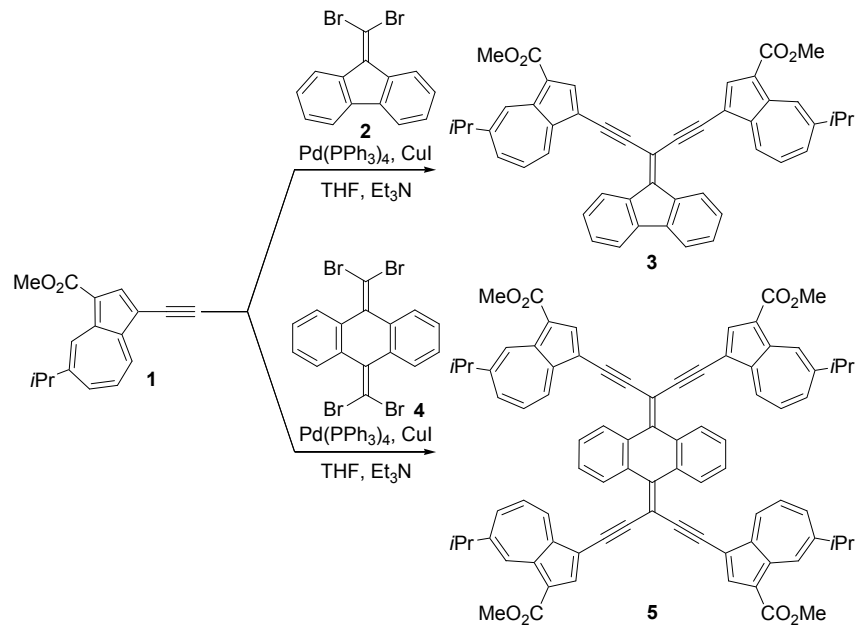

$$
\text { Scheme } 1 . \quad \text { Synthesis of }
$$

9-[bis(3-methoxycarbonyl-5-isopropyl-1-azulenylethynyl)methylene]-9H-fl uorene

9,10-bis[bis(3-methoxycarbonyl-5-isopropyl-1-azulenylethynyl)methylene] -9,10-dihydroanthracene (5).

Preparation of compounds $\mathbf{8}$ and $\mathbf{1 1}$ were also examined by the Pd-catalyzed alkynylation under the similar conditions. The reaction of 2-ethynylazulene (7) with $\mathbf{2}$ in the presence of $\mathrm{Pd}\left(\mathrm{PPh}_{3}\right)_{4}$ gave 8 in $80 \%$ yield (Scheme 2). However, the reaction of 7 with 4 afforded an inseparable complex mixture containing a small amount of 11. ${ }^{[12]}$ These results should be ascribed to the poorer reactivity of 7 compared with that of 1-ethynylazulene (1) under the Pd-catalyzed cross-coupling conditions. Thus, the ene-diyne 11 was synthesized by the reaction of 2-iodoazulene $(6)^{[8 a]}$ with 9,10 -bis(diethynylmethylene)-9,10-dihydroanthracene (10), which was prepared by the procedure reported by us, previously, ${ }^{[6]}$ in the presence of $\mathrm{Pd}\left(\mathrm{PPh}_{3}\right)_{4}$ in $57 \%$ yield (Scheme 3) These novel azulene-substituted ene-diyne derivatives $3,5,8$ and 11 possess a fair solubility in chloroform, dichloromethane, and so on. ${ }^{[13]}$ Moreover, they are stable and show no decomposition even after several weeks at room temperature.

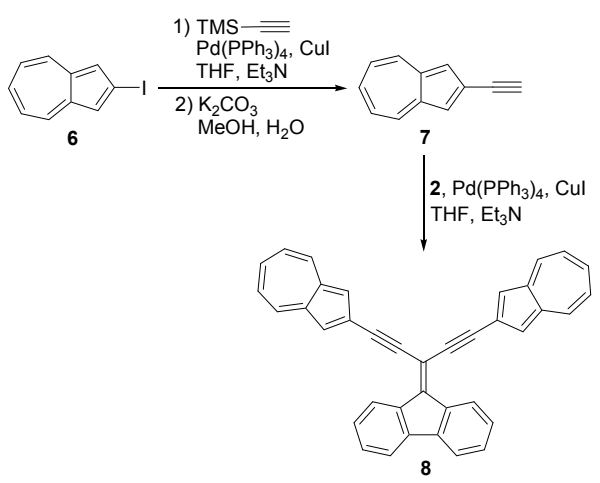

Scheme 2. Synthesis of 9-[bis(2-azulenylethynyl)methylene]-9H-fluorene (8).

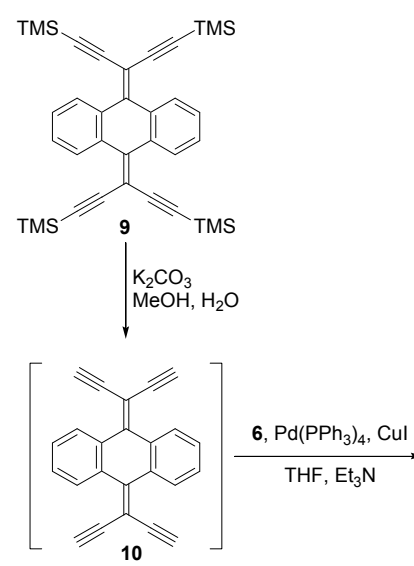

3.

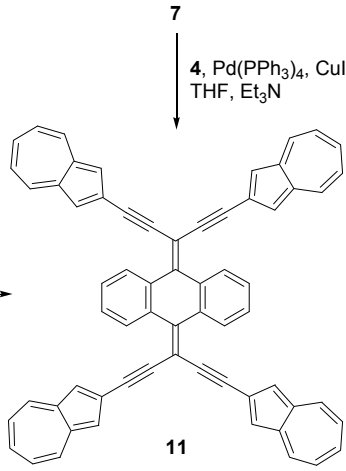

Synthesis of

Scheme 9,10-bis[bis(2-azulenylethynyl)methylene]-9,10-dihydroanthracene (11).

\section{Properties}

These new compounds were fully characterized by the spectral data, as shown in the Experimental Section. Mass spectra of 3, 5, 8 and $\mathbf{1 0}$ ionized by ESI or FAB showed the correct molecular ion peaks. The characteristic stretching vibration band of the ethynyl moiety of 3, 5, 8 and 11 was observed at $v_{\max }=2162-2182 \mathrm{~cm}^{-1}$ on their IR spectra. Compounds $\mathbf{3}$ and $\mathbf{5}$ also exhibited a characteristic $\mathrm{C}=\mathrm{O}$ stretching band at $v_{\max }=1692 \mathrm{~cm}^{-1}$ and 1693 $\mathrm{cm}^{-1}$, respectively, on their IR spectra. These results are consistent with the structure of these products.

UV/Vis spectra of ene-diynes $\mathbf{3}, \mathbf{5}$ and $\mathbf{8}, \mathbf{1 1}$ in $\mathrm{CH}_{2} \mathrm{Cl}_{2}$ are shown in Figures 2 and 3, respectively. The absorption maxima $\left(\lambda_{\max }\right)$ and their coefficients $(\log \varepsilon)$ of the ene-diynes $3, \mathbf{5}, \mathbf{8}$ and $\mathbf{1 1}$ are summarized in the Experimental Section. The UV/Vis spectra of 3, 5, 8 and 11 showed characteristic weak absorptions arising from the azulene system in the visible region. The extinction coefficients increased with the number of azulene rings. Compound 3 exhibited relatively strong two absorptions at $\lambda_{\max }=454 \mathrm{~nm}$ and $475 \mathrm{~nm}$ in $\mathrm{CH}_{2} \mathrm{Cl}_{2}$. When the solvent was changed to less polar $10 \% \mathrm{CH}_{2} \mathrm{Cl}_{2} /$ hexane, the two absorption bands of $\mathbf{3}$ showed some hypsochromic shift to $\lambda_{\max }=447 \mathrm{~nm}$ and $471 \mathrm{~nm}$, respectively. Two absorption bands displayed in compound 5 at $\lambda_{\max }=425 \mathrm{~nm}$ and $508 \mathrm{~nm}$ in $\mathrm{CH}_{2} \mathrm{Cl}_{2}$ also exhibited blue-shits by $2 \mathrm{~nm}$ and $6 \mathrm{~nm}$ $\left(\lambda_{\max }=423 \mathrm{~nm}\right.$ and $\left.502 \mathrm{~nm}\right)$, respectively, in $10 \% \mathrm{CH}_{2} \mathrm{Cl}_{2} /$ hexane. Larger absorption coefficients of compound $\mathbf{5}$ in the visible region compared with those of $\mathbf{3}$ are attributable to the increment of the 
number of substituted 1-azulenyl groups (Figure 2). Ene-diyne derivative $\mathbf{8}$ substituted by 2-azulenyl groups showed a broad absorption with fine structures at around $400-500 \mathrm{~nm}$ in $\mathrm{CH}_{2} \mathrm{Cl}_{2}$ (Figure 3). Compound 11 exhibited intense two absorption bands at $\lambda_{\max }=403 \mathrm{~nm}$ and $490 \mathrm{~nm}$. A slight hypsochromic shift was also observed in $\mathbf{1 1}$ when the solvent was changed to $10 \%$ $\mathrm{CH}_{2} \mathrm{Cl}_{2} /$ hexane $\left(\lambda_{\max }=400 \mathrm{~nm}\right.$ and $\left.487 \mathrm{~nm}\right)$. Recently, we have reported the preparation of similar ene-diyne derivatives substituted by ferrocenyl groups with a solvatochromic property. ${ }^{[\mathrm{g}]}$ Smaller shift-value of the absorption maxima for the azulene derivatives compared with that of the ferrocene derivatives should be ascribed to the lower polarity of azulene derivatives rather than ferrocene derivatives in the excited state. The longest absorption maximum of 11 in $\mathrm{CH}_{2} \mathrm{Cl}_{2}$ exhibited bathochromic shift compared with that of $8\left(\lambda_{\max }=460(\mathrm{sh}) \mathrm{nm}\right)$ in the same solvent, resulting from the extension of the $\pi$-electron system by the anthraquinodimethane unit. The absorption bands of $\mathbf{5}$ and $\mathbf{1 1}$ are resembled in shape each other, although there is a difference in the position of substitution on the azulene rings. These results should indicate the greater contribution of the anthraquinodimethane unit rather than that of azulene rings toward the absorption bands on the $\mathrm{UV} / \mathrm{Vis}$ spectra.

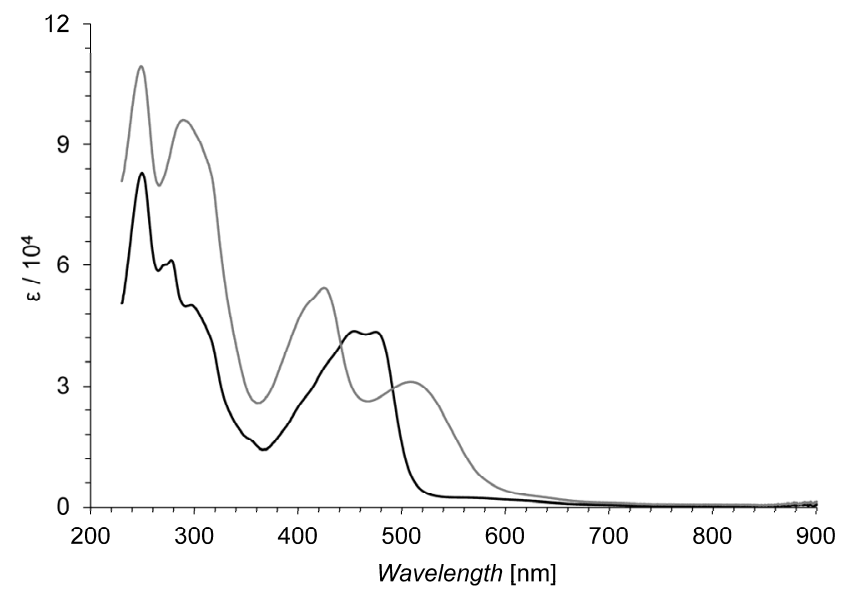

Figure 2. UV/Vis spectra of 3 (black line) and 5 (gray line) in dichloromethane.

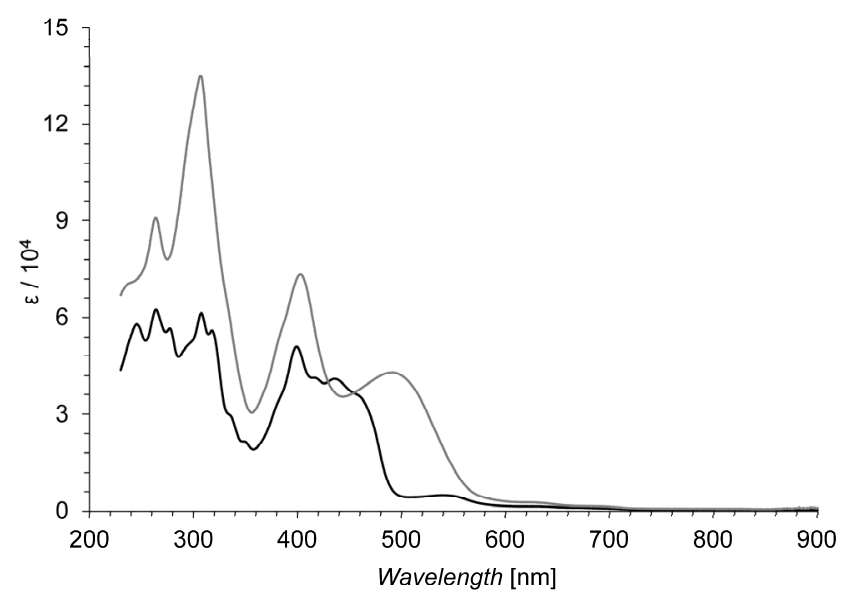

Figure 3. UV/Vis spectra of $\mathbf{8}$ (black line) and $\mathbf{1 1}$ (gray line) in dichloromethane.

\section{Electrochemistry}

To clarify the electrochemical properties, the redox behavior of ene-diyne derivatives $\mathbf{3}, \mathbf{5}, \mathbf{8}$ and $\mathbf{1 1}$ was examined by $\mathrm{CV}$ and DPV. Measurements were carried out with a standard three-electrode configuration. Tetraethylammonium perchlorate $(0.1 \mathrm{M})$ in benzonitrile was used as a supporting electrolyte with platinum wire and disk as auxiliary and working electrodes, respectively. All measurements were carried out under an argon atmosphere, and potentials were related to an $\mathrm{Ag} / \mathrm{Ag}^{+}$reference electrode and $\mathrm{Fc} / \mathrm{Fc}^{+}$as an internal reference, which discharges at $+0.15 \mathrm{~V}$. The redox potentials (in volts vs. $\mathrm{Ag} / \mathrm{AgNO}_{3}$ ) of $\mathbf{3}, \mathbf{5}, \mathbf{8}$ and $\mathbf{1 1}$ are summarized in Table 1.

Table 1. Redox potentials ${ }^{[a]}$ of ene-diynes $\mathbf{3 , 5 , 8}$ and $\mathbf{1 1}$.

\begin{tabular}{lllll}
\hline Sample & Method & $E_{1}{ }^{\text {red }}[\mathrm{V}]$ & $E_{2}^{\text {red }}[\mathrm{V}]$ & $E_{3}{ }^{\text {red }}[\mathrm{V}]$ \\
\hline $\mathbf{3}$ & (DPV) & $(-1.48)$ & $(-1.78)$ & \\
$\mathbf{5}$ & (DPV) & $(-1.48)$ & $(-1.55)$ & $(-1.67)$ \\
$\mathbf{8}$ & CV & -1.35 & -1.59 & \\
& (DPV) & $(-1.33)$ & $(-1.57)$ & $(-1.94)$ \\
$\mathbf{1 1}$ & CV & -1.21 & & \\
& (DPV) & $(-1.19)$ & $(-1.65)$ & $(-1.93)$ \\
\hline
\end{tabular}

[a] Redox potentials were measured by $\mathrm{CV}$ and DPV [V vs. $\mathrm{Ag} / \mathrm{AgNO}_{3}, 1$ $\mathrm{mM}$ in benzonitrile containing $\mathrm{Et}_{4} \mathrm{NClO}_{4}(0.1 \mathrm{M})$, Pt electrode (internal diameter: $1.6 \mathrm{~mm}$ ), scan rate $=100 \mathrm{mVs}^{-1}$, and $\left.\mathrm{Fc} / \mathrm{Fc}^{+}=+0.15 \mathrm{~V}\right]$. In the case of reversible waves, redox potentials measured by $\mathrm{CV}$ are presented. The peak potentials measured by DPV are shown in parentheses.

Although reversible reduction waves were observed in ene-diynes $\mathbf{8}$ and $\mathbf{1 1}$ substituted by 2-azulenyl groups, reduction waves of ene-diynes $\mathbf{3}$ and $\mathbf{5}$ with 1-azulenyl substituents did not show reversibility on $\mathrm{CV}$. Electrochemical reduction of $\mathbf{3}$ exhibited irreversible reduction waves at $-1.48 \mathrm{~V}$ and $-1.78 \mathrm{~V}$ on DPV. Irreversible reduction waves were also observed in $\mathbf{5}$ at $-1.48 \mathrm{~V}$, $-1.55 \mathrm{~V}$ and $-1.67 \mathrm{~V}$ on DPV. Irreversibility of the reduction wave of $\mathbf{3}$ and $\mathbf{5}$ indicates the instability of the radical anionic spices, caused by the electron-donating nature of the substituted 1 -azulenyl groups. The first reduction potential of the ene-diynes 3 and $\mathbf{5}$ is the same value. Thus, influence of fluorene and anthraquinodimethane units is small in the electrochemical reduction of the ene-diynes $\mathbf{3}$ and $\mathbf{5}$ with 1-azulenyl substituents.

The ene-diyne derivative $\mathbf{8}$ exhibited a three-step reduction wave, in which the third-step is irreversible. The potentials were identified by DPV as $-1.33 \mathrm{~V},-1.57 \mathrm{~V}$ and $-1.94 \mathrm{~V}$, to form up to a trianionic species (Figure 4). Thus, the redox system of $\mathbf{8}$ could be considered to be a $\mathrm{V}-\mathrm{C}$ hybrid ${ }^{[14]}$ as illustrated in Scheme 4. The ene-diyne derivative $\mathbf{1 1}$ also exhibited a three-step reduction wave in DPV. The first reduction wave at $-1.21 \mathrm{~V}$ showed reversibility on CV (Figure 5). The first reduction potentials of the ene-diyne derivatives $\mathbf{8}$ and $\mathbf{1 1}$ with 2-azulenyl substituents were less negative than those of the corresponding 1-azulenyl derivatives $\mathbf{3}$ and $\mathbf{5}$. This indicates that the 2 -azulenyl substituents embedded in the ene-diyne systems increase electron affinity to decrease the LUMO level of the molecule rather than 1-azulenyl substituents, due to their electron-withdrawing nature. 


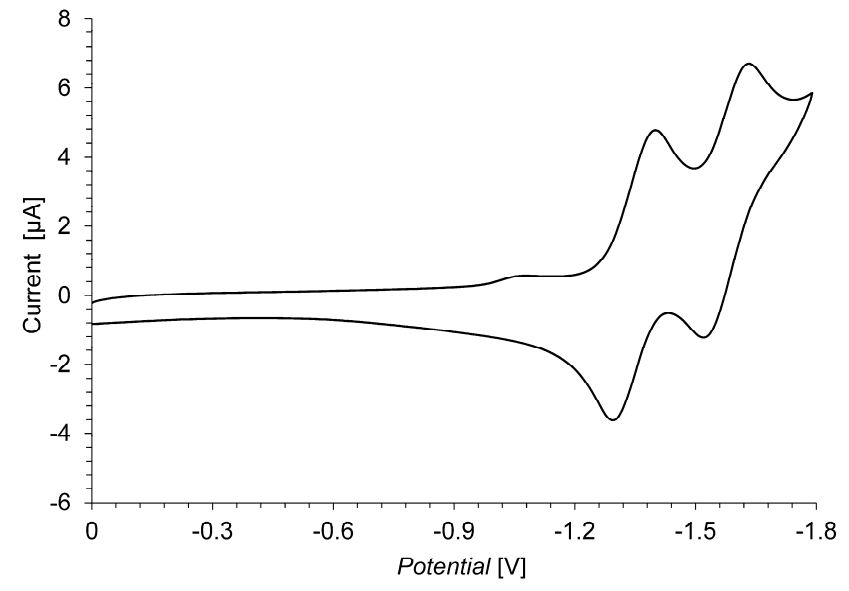

Figure 4. Cyclic voltammograms of the reduction of $8(1 \mathrm{mM})$ in benzonitrile containing $\mathrm{Et}_{4} \mathrm{NClO}_{4}(0.1 \mathrm{M})$ as a supporting electrolyte; scan rate $=100 \mathrm{mVs}^{-1}$.

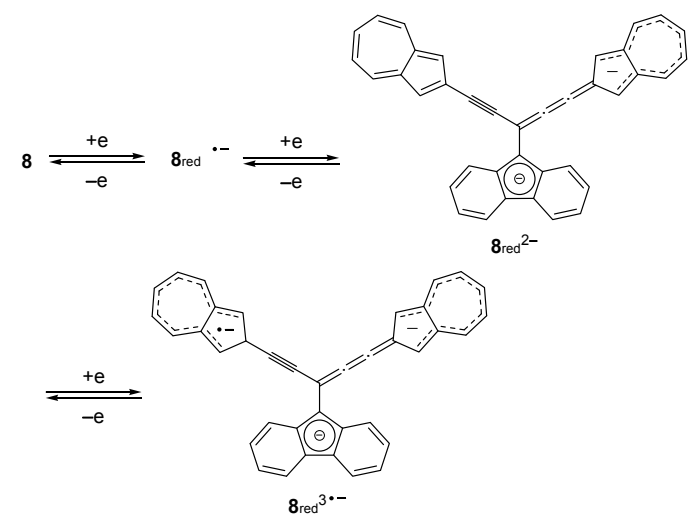

Scheme 4. Presumed redox behavior of $\mathbf{8}$ by the electrochemical reduction.

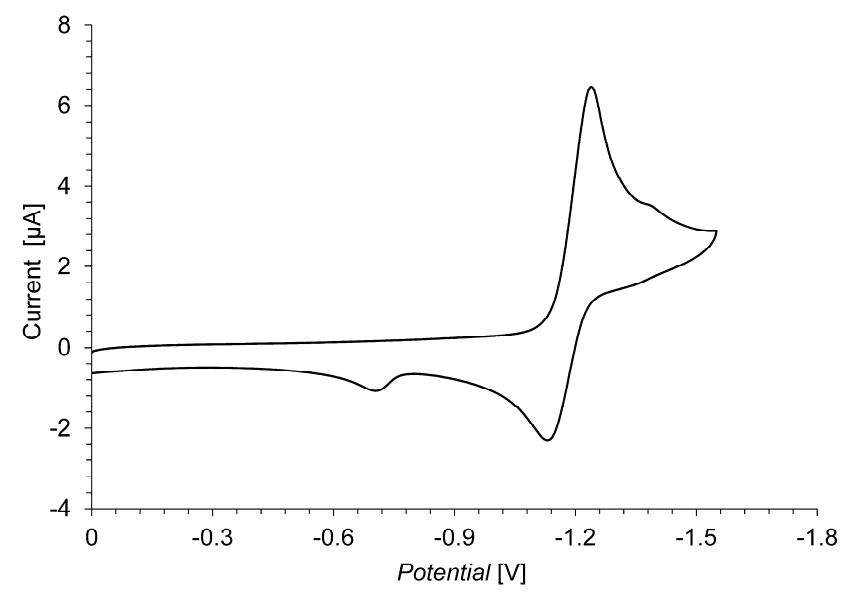

Figure 5. Cyclic voltammograms of the reduction of $11(1 \mathrm{mM})$ in benzonitrile containing $\mathrm{Et}_{4} \mathrm{NClO}_{4}(0.1 \mathrm{M})$ as a supporting electrolyte; scan rate $=100 \mathrm{mVs}^{-1}$.

Electrochromism is observed in reversible redox systems that exhibit significant color changes in their different oxidation states. Stabilization of the redox cycle is very important in the construction of electrochromic materials because the molecules utilized for these applications require high redox stabilities. ${ }^{[15]} \mathrm{We}$ have reported the synthesis of various azulene-substituted redox-active chromophores with the aim of creating stabilized electrochromic materials. ${ }^{[8,9,10,16]}$ In that studies, we have revealed the ene-diyne units combined with 6-azulenyl groups as terminal groups provided stabilized electrochromic materials exhibiting strong absorptions in the near-infrared region in their two-electron reduced state. ${ }^{[6,16,17]}$ The ene-diyne derivatives $\mathbf{3}, \mathbf{5}, \mathbf{8}$ and $\mathbf{1 1}$ substituted by 1 - and 2-azulenyl groups might exemplify a new class of electrochromic materials, as well as the ene-diyne systems with 6-azulenyl substituents. Thus, the visible spectra of the ene-diynes $3, \mathbf{5}, \mathbf{8}$ and $\mathbf{1 1}$ were monitored to determine the color changes during the electrochemical reactions.

Constant-current electrolysis was applied to the solution of ene-diynes 3, 5, 8 and $\mathbf{1 1}$ with a platinum mesh as the working electrode and a wire counter electrode. Visible spectra were measured in degassed benzonitrile containing $\mathrm{Et}_{4} \mathrm{NClO}_{4}(0.1 \mathrm{M})$ as the supporting electrolyte at room temperature under the electrochemical conditions. The yellow color of the solution of $\mathbf{3}$ changed to deep purple during electrochemical reduction with the development of a new absorption band in the visible region at $\lambda_{\max }$ $=590 \mathrm{~nm}$. Reverse oxidation of the deep purple solution regenerated the visible spectra of the yellow colored 3, but incompletely (Figure 6). When the UV/Vis spectra of 5 were monitored under the electrochemical reduction conditions, the absorption of 5 at $\lambda_{\max }=520 \mathrm{~nm}$ in the visible region gradually decreased together with the development of a new absorption in the visible region at $\lambda_{\max }=630 \mathrm{~nm}$. Reverse oxidation decreased the new absorption band, but did not regenerate the absorption band of 5. These results indicate instability of the anionic species of the 1-azulenyl derivatives, in consistent with the results on $\mathrm{CV}$.
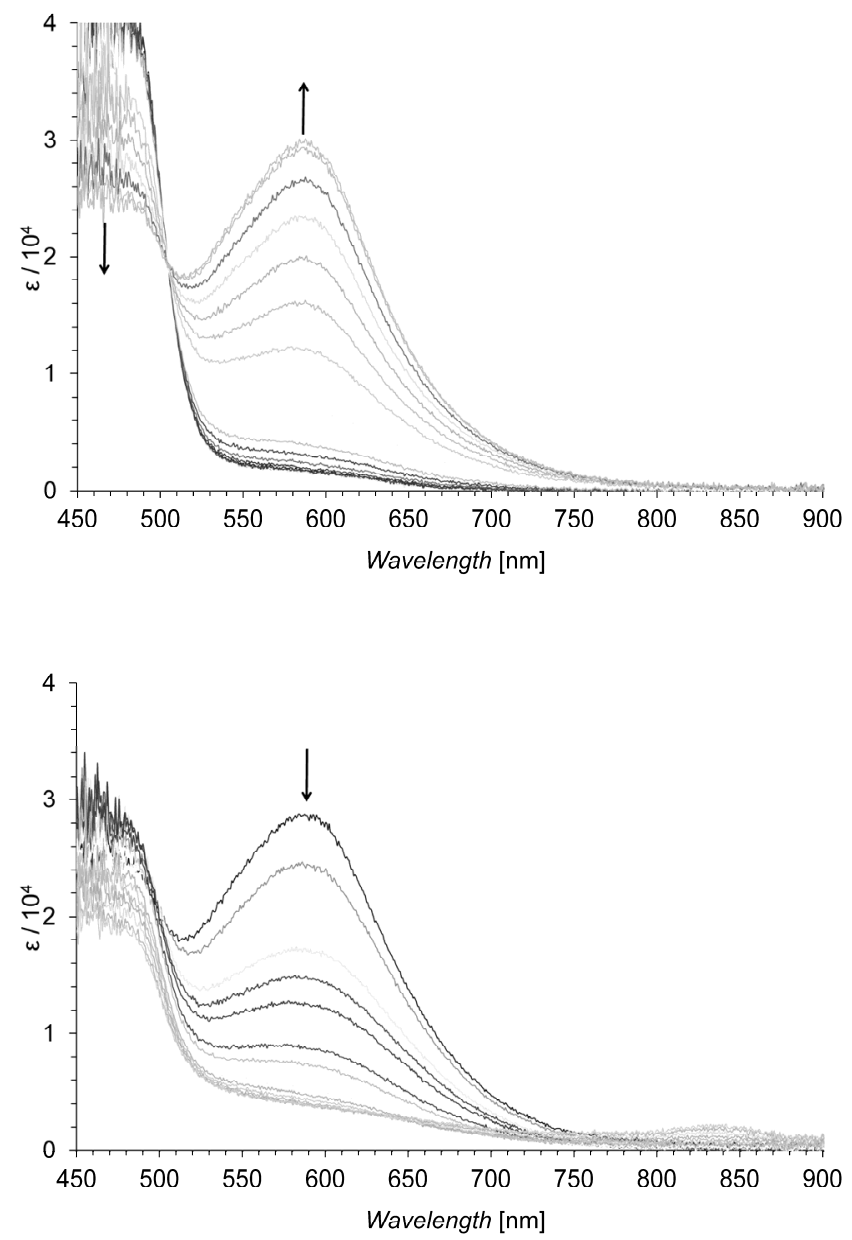
Figure 6. Continuous change in the UV/Vis spectra of 3: constant-current electrochemical reduction (100 $\mu \mathrm{A}$, top) and reverse oxidation of the reduced species $\left(100 \mu \mathrm{A}\right.$, bottom) in benzonitrile containing $\mathrm{Et}_{4} \mathrm{NClO}_{4}(0.1$ $\mathrm{M})$ at $30 \mathrm{sec}$ intervals.

Significant color changes were also observed in ene-diynes $\mathbf{8}$ and 11 with 2-azulenyl groups. When the visible spectral changes of $\mathbf{8}$ were measured during the electrochemical reduction, absorption bands in the visible region at $\lambda_{\max }=560 \mathrm{~nm}, 635 \mathrm{~nm}$ and $720 \mathrm{~nm}$ gradually increased with the development of a new absorption band in the near-infrared region, along with the isosbestic point at $485 \mathrm{~nm}$. Reverse oxidation decreased the new absorption bands and regenerated the original absorptions of the yellow-colored 8 (Figure 7). The absorption band around $\lambda_{\max }=$ $870 \mathrm{~nm}$ spread into the near-infrared region was generated on the spectral change of $\mathbf{1 1}$ under the electrochemical reduction conditions. The color of the solution of $\mathbf{1 1}$ gradually changed from red to blue during the electrochemical reduction. Reverse oxidation decreased the new absorption band in the near-infrared region and regenerated the original color of $\mathbf{1 1 .}$
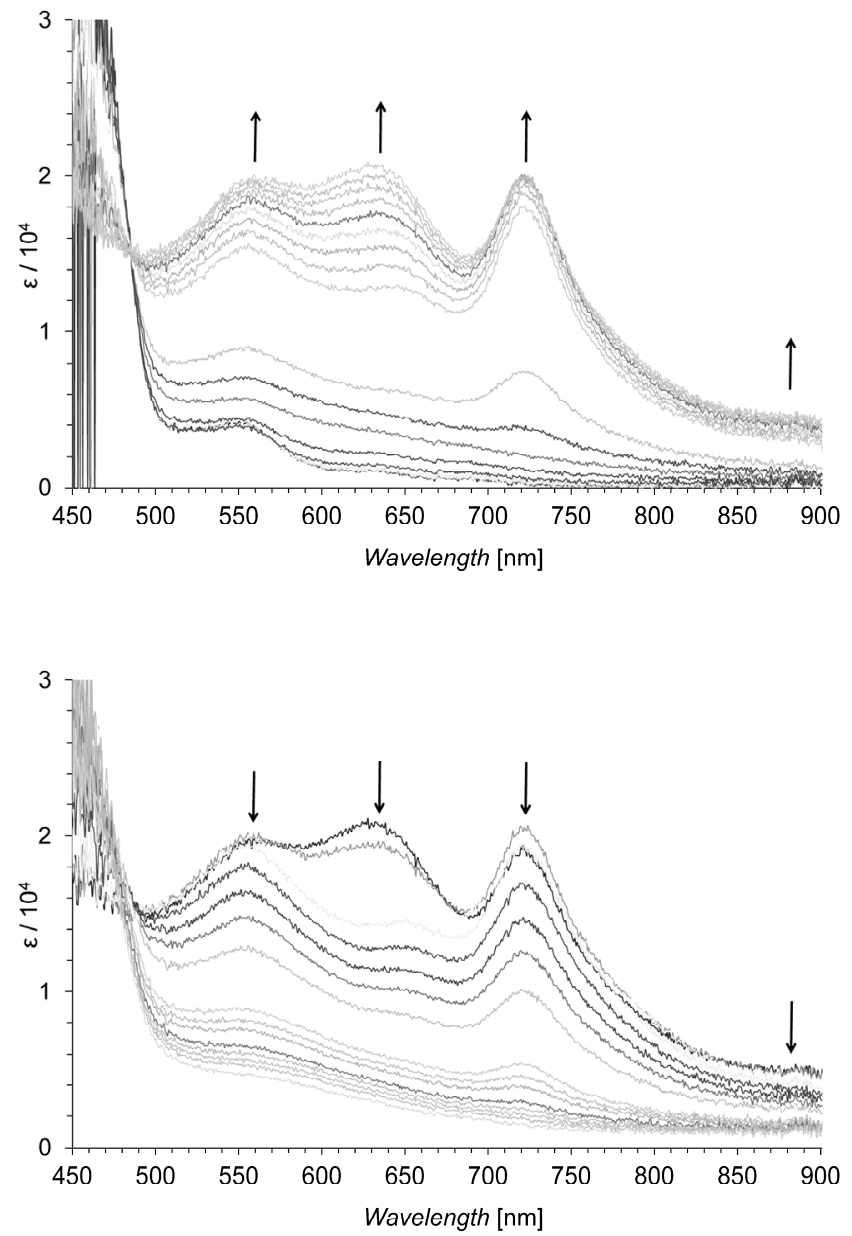

Figure 7. Continuous change in the UV/Vis spectra of 8: constant-current electrochemical reduction (100 $\mu \mathrm{A}$, top) and reverse oxidation of the reduced species $\left(100 \mu \mathrm{A}\right.$, bottom) in benzonitrile containing $\mathrm{Et}_{4} \mathrm{NClO}_{4}(0.1$ M) at $30 \mathrm{sec}$ intervals.

From the results described above, the new ene-diyne derivatives 8 and 11 substituted by the 2-azulenyl groups were revealed to display certain reversibility under the electrochemical conditions with characteristic absorption bands in the visible and near-infrared region, respectively. Thus, the ene-diyne derivatives $\mathbf{8}$ and $\mathbf{1 1}$ substituted by 2 -azulenyl groups also exhibited high reversibility in their electrochromic behavior, which should be ascribed to the stabilization of anionic species by the substituted azulene ring, as well as ene-diyne derivatives with 6-azulenyl groups.

\section{Conclusions}

Several ene-diyne derivatives connected with 1- and 2-azulenyl groups were prepared by Sonogashira-Hagihara cross-coupling reactions. An analysis by $\mathrm{CV}$ showed that compounds $\mathbf{8}$ and $\mathbf{1 1}$ exhibited reversible reduction waves, respectively, although the ene-diynes $\mathbf{3}$ and $\mathbf{5}$ substituted by 1-azulenyl groups showed an irreversible wave. Moreover, a significant color change was observed during the electrochemical reduction. In particular, ene-diyne derivatives $\mathbf{8}$ and $\mathbf{1 1}$ substituted by 2-azulenyl groups exhibited a significant color change during the electrochemical reduction. These results showed that the ene-diyne derivatives with 2-azulenyl groups behave as $\mathrm{V}-\mathrm{C}$ hybrid in the view of the formation of closed-shell system formed by the two-electron reduction.

\section{Experimental Section}

\section{General}

Melting points were determined with a Yanagimoto MPS3 micro melting apparatus and are uncorrected. High resolution mass spectra were obtained with a Bruker Daltonics APEX III instrument. IR and UV/Vis spectra were measured with JASCO FT/IR-4100 and Shimadzu UV-2550 spectrophotometer. ${ }^{1} \mathrm{H}$ and ${ }^{13} \mathrm{C}$ NMR spectra were recorded with a JEOL ECA 500 at $500 \mathrm{MHz}$ and $125 \mathrm{MHz}$, respectively. Voltammetry measurements were carried out with a BAS 100B/W electrochemical workstation equipped with $\mathrm{Pt}$ working and auxiliary electrodes and a reference electrode formed from $\mathrm{Ag} / \mathrm{AgNO}_{3}(0.01 \mathrm{M})$ in acetonitrile containing tetrabutylammonium perchlorate $(0.1 \mathrm{M})$. Elemental analyses were performed at the Research and Analytical Center for Giant Molecules, Graduate School of Science, Tohoku University.

9-[Bis(3-methoxycarbonyl-5-isopropyl-1-azulenylethynyl)methylene]-9 $\boldsymbol{H}$-fluorene (3): To a degassed solution of 1 (606 mg, $2.40 \mathrm{mmol}), 2$ (333 $\mathrm{mg}, 1.00 \mathrm{mmol})$, and $\mathrm{CuI}(38 \mathrm{mg}, 0.20 \mathrm{mmol})$ in triethylamine $(10 \mathrm{~mL})$ and THF (10 mL) was added tetrakis(triphenylphosphine)palladium (115 mg, $0.10 \mathrm{mmol}$ ). The resulting mixture was stirred at $50{ }^{\circ} \mathrm{C}$ for $12 \mathrm{~h}$ under an $\mathrm{Ar}$ atmosphere. The reaction mixture was poured into a $10 \% \mathrm{NH}_{4} \mathrm{Cl}$ solution and extracted with $\mathrm{CH}_{2} \mathrm{Cl}_{2}$. The organic layer was washed with brine, dried over $\mathrm{Na}_{2} \mathrm{SO}_{4}$, and concentrated under reduced pressure. The residue was purified by column chromatography on silica gel with $\mathrm{CH}_{2} \mathrm{Cl}_{2}$ to give 3 (604 mg, 89\%) as brown crystals. M.p. $238.0-240.0{ }^{\circ} \mathrm{C}\left(\mathrm{CH}_{2} \mathrm{Cl}_{2} / \mathrm{MeOH}\right)$. IR $\left(\mathrm{KBr}\right.$ disk): $v_{\max }=2162(\mathrm{C} \equiv \mathrm{C}), 1692(\mathrm{C}=\mathrm{O}) \mathrm{cm}^{-1}$. UV/Vis $\left(\mathrm{CH}_{2} \mathrm{Cl}_{2}\right)$ : $\lambda_{\max }(\log \varepsilon)=250$ (4.92), $268 \mathrm{sh}$ (4.77), 278 (4.79), 297 (4.70), $316 \mathrm{sh}$ (4.62), $400 \mathrm{sh}$ (4.39), $424 \mathrm{sh}$ (4.53), 454 (4.64), 475 (4.64), $570 \mathrm{sh}$ (3.35), $600 \mathrm{sh}(3.26) \mathrm{nm}$. UV/Vis $\left(10 \% \mathrm{CH}_{2} \mathrm{Cl}_{2} /\right.$ hexane): $\lambda_{\max }(\log \varepsilon)=248$ (4.94), $270 \mathrm{sh}$ (4.78), 277 (4.79), 298 (4.68), $316 \mathrm{sh}$ (4.66), $392 \mathrm{sh}$ (4.38), $422 \mathrm{sh}$ (4.58), 447 (4.65), 471 (4.65), $570 \mathrm{sh}$ (3.36), $586 \mathrm{sh}$ (3.25) nm. ${ }^{1} \mathrm{H}$ NMR $\left(500 \mathrm{MHz}, \mathrm{CDCl}_{3}\right): \delta_{\mathrm{H}}=9.79(\mathrm{~d}, J=2.0 \mathrm{~Hz}, 2 \mathrm{H}, \mathrm{H}-4), 8.93(\mathrm{~d}, J=7.5 \mathrm{~Hz}$, 2H, H-1',8'), 8.70 (d, J=7.5 Hz, 2H, H-4',5'), 8.60 (s, 2H, H-2), 7.85 (d, J $=10.0 \mathrm{~Hz}, 2 \mathrm{H}, \mathrm{H}-8), 7.73(\mathrm{~d}, J=10.0 \mathrm{~Hz}, 2 \mathrm{H}, \mathrm{H}-6), 7.53(\mathrm{dd}, J=10.0$, $10.0 \mathrm{~Hz}, 2 \mathrm{H}, \mathrm{H}-7$ ), 7.41 (m, 4H, H-2',3',6',7'), 3.99 (s, 6H, $\mathrm{CO}_{2} \mathrm{Me}$ ), 3.26 (sept, $J=6.8 \mathrm{~Hz}, 2 \mathrm{H}, i \mathrm{Pr}), 1.45(\mathrm{~d}, J=6.8 \mathrm{~Hz}, 12 \mathrm{H}, i \mathrm{Pr}) \mathrm{ppm} .{ }^{13} \mathrm{C}$ NMR $\left(125 \mathrm{MHz}, \mathrm{CDCl}_{3}\right): \delta_{\mathrm{C}}=165.46\left(\mathrm{CO}_{2} \mathrm{Me}\right), 151.40(\mathrm{C}-5), 145.59(\mathrm{C}-3 \mathrm{a}$ or 8a), 142.95 (C-2), 142.18 (C-3a or 8a), 141.82 (C-9'), 139.95 (C-8), 139.82 (C-4), 138.79 (C-1a',8a' or 4a',5a'), 137.90 (C-1a',8a' or 4a',5a'), 136.63 
(C-4',5'), $129.01\left(\mathrm{C}-2^{\prime}, 7^{\prime}\right.$ ' or 3', 6'), $128.24(\mathrm{C}-7), 127.39\left(\mathrm{C}^{\prime} 2^{\prime}, 7^{\prime}\right.$ or $\left.3^{\prime}, 6^{\prime}\right)$, 125.24 (C-1', $\left.8^{\prime}\right), 119.67$ (C-6), 115.81 (C-3), 108.91 (C-1), 102.79 (C-10'), $94.55(\mathrm{C} \equiv \mathrm{C}), 94.49(\mathrm{C} \equiv \mathrm{C}), 51.41\left(\mathrm{CO}_{2} \mathrm{Me}\right), 39.43(i \operatorname{Pr}), 24.74(i \operatorname{Pr}) \mathrm{ppm}$. HRMS (ESI): calcd for $\mathrm{C}_{48} \mathrm{H}_{38} \mathrm{O}_{4}+\mathrm{Na}^{+}[\mathrm{M}+\mathrm{Na}]^{+}$701.2668; found: 701.2662. Anal. calcd for $\mathrm{C}_{48} \mathrm{H}_{38} \mathrm{O}_{4} \cdot 2 / 3 \mathrm{H}_{2} \mathrm{O}$ (678.81): C 83.45, H 5.74; found: C, 83.49, H 5.74.

9,10-Bis[bis(3-methoxycarbonyl-5-isopropyl-1-azulenylethynyl)-methyl ene]-9,10-dihydroanthracene (5): To a degassed solution of $1(606 \mathrm{mg}$, $2.40 \mathrm{mmol}), 4(260 \mathrm{mg}, 0.50 \mathrm{mmol})$, and $\mathrm{CuI}(38 \mathrm{mg}, 0.20 \mathrm{mmol})$ in triethylamine $(10 \mathrm{~mL})$ and THF $(10 \mathrm{~mL})$ was added tetrakis(triphenylphosphine)palladium $(115 \mathrm{mg}, 0.10 \mathrm{mmol})$. The resulting mixture was stirred at $50{ }^{\circ} \mathrm{C}$ for $24 \mathrm{~h}$ under an $\mathrm{Ar}$ atmosphere. The reaction mixture was poured into a $10 \% \mathrm{NH}_{4} \mathrm{Cl}$ solution and extracted with $\mathrm{CH}_{2} \mathrm{Cl}_{2}$. The organic layer was washed with brine, dried over $\mathrm{Na}_{2} \mathrm{SO}_{4}$, and concentrated under reduced pressure. The residue was purified by column chromatography on silica gel with $\mathrm{CH}_{2} \mathrm{Cl}_{2}$ to give 5 (446 mg, 74\%) as reddish-brown crystals. M.p. $>300.0{ }^{\circ} \mathrm{C}(\mathrm{AcOEt})$. IR $\left(\mathrm{KBr}\right.$ disk): $v_{\max }=$ $2178(\mathrm{C} \equiv \mathrm{C}), 1693(\mathrm{C}=\mathrm{O})) \mathrm{cm}^{-1}$. UV/Vis $\left(\mathrm{CH}_{2} \mathrm{Cl}_{2}\right): \lambda_{\max }(\log \varepsilon)=249(5.04)$, 289 (4.98), $315 \mathrm{sh}$ (4.92), $403 \mathrm{sh}$ (4.68), 425 (4.74), 508 (4.49), $635 \mathrm{sh}$ (3.39) $\mathrm{nm}$. UV/Vis $\left(10 \% \mathrm{CH}_{2} \mathrm{Cl}_{2} /\right.$ hexane): $\lambda_{\max }(\log \varepsilon)=248(5.04), 283$ (4.95), $313 \mathrm{sh}$ (4.90), $403 \mathrm{sh}$ (4.68), 423 (4.73), 502 (4.45), $635 \mathrm{sh}$ (3.34) nm. ${ }^{1} \mathrm{H}$ NMR ( $500 \mathrm{MHz}, \mathrm{CDCl}_{3}$ ): $\delta_{\mathrm{H}}=9.71(\mathrm{~d}, J=1.5 \mathrm{~Hz}, 4 \mathrm{H}, \mathrm{H}-4), 8.64$ (dd, $\left.J=6.0,3.5 \mathrm{~Hz}, 4 \mathrm{H}, \mathrm{H}-1^{\prime}, 4^{\prime}, 5^{\prime}, 8^{\prime}\right), 8.57$ (d, $J=9.5 \mathrm{~Hz}, 4 \mathrm{H}, \mathrm{H}-8$ ), 8.52 (s, $4 \mathrm{H}, \mathrm{H}-2), 7.70$ (d, $J=9.5 \mathrm{~Hz}, 4 \mathrm{H}, \mathrm{H}-6), 7.54$ (dd, $J=6.0,3.5 \mathrm{~Hz}, 4 \mathrm{H}$, H-2', ', ', 6', ' '), 7.36 (dd, $J=9.5,9.5 \mathrm{~Hz}, 4 \mathrm{H}, \mathrm{H}-7), 3.97$ (s, $12 \mathrm{H}, \mathrm{CO}_{2} \mathrm{Me}$ ), 3.21 (sept, $J=6.8 \mathrm{~Hz}, 4 \mathrm{H}, i \operatorname{Pr}$ ), $1.41(\mathrm{~d}, J=6.8 \mathrm{~Hz}, 24 \mathrm{H}, i \operatorname{Pr}) \mathrm{ppm} .{ }^{13} \mathrm{C}$ NMR $\left(125 \mathrm{MHz}, \mathrm{CDCl}_{3}\right): \delta_{\mathrm{C}}=165.42\left(\mathrm{CO}_{2} \mathrm{Me}\right), 150.78(\mathrm{C}-5), 145.46$ (C-3a or 8a), 143.35, 142.75 (C-2), 141.50 (C-3a or 8a), 139.34 (C-6), 138.48 (C-4), 136.82 (C-8), 135.33, 135.18, 127.73 (C-7), 127.61 (C-1',4',5', 8'), 126.95 (C-2',3',6',7'), 115.72 (C-3), 109.48 (C-1), 94.48 $(\mathrm{C} \equiv \mathrm{C}), 89.92(\mathrm{C} \equiv \mathrm{C}), 51.14\left(\mathrm{CO}_{2} \mathrm{Me}\right), 39.28(i \mathrm{Pr}), 24.58$ (iPr) ppm. HRMS (ESI): calcd for $\mathrm{C}_{84} \mathrm{H}_{68} \mathrm{O}_{8}+\mathrm{Na}^{+}[\mathrm{M}+\mathrm{Na}]^{+}$1227.4812; found: 1227.4806 . Anal. calcd for $\mathrm{C}_{84} \mathrm{H}_{68} \mathrm{O}_{8}$ (1205.43): $\mathrm{C} 83.70, \mathrm{H}, 5.69$; found: $\mathrm{C} 83.57, \mathrm{H}$ 5.80 .

9-[Bis(2-azulenylethynyl)methylene]-9H-fluorene (8): To a degassed solution of 7 (365 mg, $2.40 \mathrm{mmol}), 2$ (333 mg, $1.00 \mathrm{mmol})$, and CuI (38 mg, $0.20 \mathrm{mmol})$ in triethylamine $(10 \mathrm{~mL})$ and THF $(10 \mathrm{~mL})$ was added tetrakis(triphenylphosphine)palladium $(115 \mathrm{mg}, 0.10 \mathrm{mmol})$. The resulting mixture was stirred at $50{ }^{\circ} \mathrm{C}$ for $12 \mathrm{~h}$ under an $\mathrm{Ar}$ atmosphere. The reaction mixture was poured into a $10 \% \mathrm{NH}_{4} \mathrm{Cl}$ solution and extracted with $\mathrm{CH}_{2} \mathrm{Cl}_{2}$. The organic layer was washed with brine, dried over $\mathrm{Na}_{2} \mathrm{SO}_{4}$, and concentrated under reduced pressure. The residue was purified by column chromatography on silica gel with $\mathrm{CH}_{2} \mathrm{Cl}_{2}$ to give $8(383 \mathrm{mg}, 80 \%)$ as brown crystals. M.p. $208.0-209.5^{\circ} \mathrm{C}\left(\mathrm{CH}_{2} \mathrm{Cl}_{2}\right)$. IR ( $\mathrm{KBr}$ disk): $v_{\max }=2176$ $(\mathrm{C} \equiv \mathrm{C}) \mathrm{cm}^{-1}$. UV/Vis $\left(\mathrm{CH}_{2} \mathrm{Cl}_{2}\right): \lambda_{\max }(\log \varepsilon)=246$ (4.76), 264 (4.79), 277 (4.75), 308 (4.79), 318 (4.75), 335 sh (4.47), 349 (4.33), 399 (4.71), 416 (4.62), 436 (4.61), $460 \mathrm{sh}$ (4.55), 539 (3.69), $625 \mathrm{sh}$ (3.15), $688 \mathrm{sh}$ (2.94) $\mathrm{nm}$. UV/Vis $\left(10 \% \mathrm{CH}_{2} \mathrm{Cl}_{2} /\right.$ hexane): $\lambda_{\max }(\log \varepsilon)=244$ (4.74), $270 \mathrm{sh}(4.74)$, 276 (4.74), 306 (4.79), 316 sh (4.74), 392 sh (4.67), 422 sh (4.59), 435 (4.61), $460 \mathrm{sh}$ (4.52), 530 (3.67), $625 \mathrm{sh}$ (3.00), $688 \mathrm{sh}(2.75) \mathrm{nm} .{ }^{1} \mathrm{H}$ NMR $\left(500 \mathrm{MHz}, \mathrm{CDCl}_{3}\right): \delta_{\mathrm{H}}=8.87\left(\mathrm{~d}, J=7.0 \mathrm{~Hz}, 2 \mathrm{H}, \mathrm{H}-1^{\prime}, 8^{\prime}\right), 8.33$ (d, $J=10.0$ $\mathrm{Hz}, 4 \mathrm{H}, \mathrm{H}-4,8), 7.70$ (d, $\left.J=7.0 \mathrm{~Hz}, 2 \mathrm{H}, \mathrm{H}-4^{\prime}, 5^{\prime}\right), 7.63$ (s, 4H, H-1,3), 7.59 (t, $J=10.0 \mathrm{~Hz}, 2 \mathrm{H}, \mathrm{H}-6), 7.38$ (m, 4H, H-2', 3', 6', ' ' $), 7.23$ (t, $J=10.0 \mathrm{~Hz}$, $4 \mathrm{H}, \mathrm{H}-5,7) \mathrm{ppm} .{ }^{13} \mathrm{C}$ NMR $\left(125 \mathrm{MHz}, \mathrm{CDCl}_{3}\right): \delta_{\mathrm{C}}=145.74(\mathrm{C}-9$ ') 140.45 (C-3a,8a), 138.25 (C-6), 137.70 (C-2), 137.30 (C-4,8), 129.71 (C-2', ,' or 3',6'), 127.68 (C-2',7' or 3',6'), 125.93 (C-1', $\left.8^{\prime}\right), 124.35$ (C-5,7), 120.89

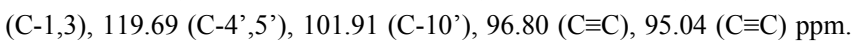
The two signals were overlapped with other signals. HRMS (ESI): calcd for $\mathrm{C}_{38} \mathrm{H}_{22}+\mathrm{Na}^{+}[\mathrm{M}+\mathrm{Na}]^{+}$501.1619; found: 501.1614. HRMS (EI): calcd for $\mathrm{C}_{38} \mathrm{H}_{22}{ }^{+}[\mathrm{M}]^{+}$478.1721; found: 478.1722. Anal. calcd for $\mathrm{C}_{38} \mathrm{H}_{22}$ (478.58): $\mathrm{C}$ 95.37, H 4.63; found: C 95.22, H 4.77.

\section{9,10-Bis[bis(2-azulenylethynyl)methylene]-9,10-dihydroanthracene}

(11): Potassium carbonate $(276 \mathrm{mg}, 2.00 \mathrm{mmol}$ ) was added to a solution of $9(147 \mathrm{mg}, 0.25 \mathrm{mmol})$ in methanol $(20 \mathrm{~mL})$. The resulting mixture was stirred at room temperature for $1 \mathrm{~h}$. After an addition of diethyl ether and water to the reaction mixture, the organic layer was separated, dried with $\mathrm{Na}_{2} \mathrm{SO}_{4}$, and concentrated under reduced pressure up to $5 \mathrm{~mL}$. 2-Iodoazulene (6) $(254 \mathrm{mg}, 1.00 \mathrm{mmol}), \mathrm{CuI}(19 \mathrm{mg}, 0.10 \mathrm{mmol})$, triethylamine $(10 \mathrm{~mL})$, and THF $(10 \mathrm{~mL})$ were added to the solution of $\mathbf{1 0}$. After an addition of tetrakis(triphenylphosphine)palladium (58 mg, 0.050 $\mathrm{mmol}$ ) to the degassed mixture, it was stirred at room temperature for $12 \mathrm{~h}$. The reaction mixture was diluted with $\mathrm{CH}_{2} \mathrm{Cl}_{2}$, washed successively with $10 \% \mathrm{NH}_{4} \mathrm{Cl}$ and brine, dried with $\mathrm{Na}_{2} \mathrm{SO}_{4}$, and concentrated under reduced pressure. The residue was purified by column chromatography on silica gel with dichloromethane to afford $\mathbf{1 1}(115 \mathrm{mg}, 57 \%)$ as reddish-brown crystals. M.p. $>300.0{ }^{\circ} \mathrm{C}\left(\mathrm{CH}_{2} \mathrm{Cl}_{2} / \mathrm{MeOH}\right)$. IR ( $\mathrm{KBr}$ disk): $v_{\max }=2182(\mathrm{C} \equiv \mathrm{C}) \mathrm{cm}^{-1}$. UV/Vis $\left(\mathrm{CH}_{2} \mathrm{Cl}_{2}\right): \lambda_{\max }(\log \varepsilon)=264$ (4.96), 307 (5.13), $383 \mathrm{sh}$ (4.74), 403 (4.87), 490 (4.63), $620 \mathrm{sh}$ (3.40), $692 \mathrm{sh}(3.12) \mathrm{nm}$. UV/Vis $(10 \%$ $\mathrm{CH}_{2} \mathrm{Cl}_{2} /$ hexane): $\lambda_{\max }(\log \varepsilon)=263$ (4.98), 306 (5.12), 383 sh (4.73), 400 (4.85), 487 (4.65), $620 \mathrm{sh}$ (3.40), $692 \mathrm{sh}(3.12) \mathrm{nm} .{ }^{1} \mathrm{H}$ NMR (500 MHz, $\left.\mathrm{CDCl}_{3}\right): \delta_{\mathrm{H}}=8.65\left(\mathrm{dd}, J=5.5,3.5 \mathrm{~Hz}, 4 \mathrm{H}, \mathrm{H}-1^{\prime}, 4^{\prime}, 5^{\prime}, 8^{\prime}\right), 8.24(\mathrm{~d}, J=9.5$ $\mathrm{Hz}, 8 \mathrm{H}, \mathrm{H}-4,8), 7.53-7.49$ (m, 8H, H-6,2',3',6', '7'), 7.50 (s, 8H, H-1,3), $7.15(\mathrm{t}, J=9.5 \mathrm{~Hz}, 8 \mathrm{H}, \mathrm{H}-5,7) \mathrm{ppm} .{ }^{13} \mathrm{C}$ NMR $\left(125 \mathrm{MHz}, \mathrm{CDCl}_{3}\right): \delta_{\mathrm{C}}=$ 146.41 (C-9',10'), 140.44 (C-3a,8a), 137.61 (C-6), 136.70 (C-4,8), 134.81, 130.47, $127.72\left(\mathrm{C}-1^{\prime}, 4^{\prime}, 5^{\prime}, 8^{\prime}\right), 127.50\left(\mathrm{C}-2^{\prime}, 3^{\prime}, 6^{\prime}, 7^{\prime}\right), 124.04(\mathrm{C}-5,7)$, 120.87 (C-1,3), 101.72 (C-11',12'), $95.79(\mathrm{C} \equiv \mathrm{C}), 93.01 \quad(\mathrm{C} \equiv \mathrm{C})$ ppm. HRMS (FAB): calcd for $\mathrm{C}_{64} \mathrm{H}_{36}{ }^{+}[\mathrm{M}]^{+}$804.2817; found: 804.2799. Anal. calcd for $\mathrm{C}_{64} \mathrm{H}_{36} \cdot \mathrm{H}_{2} \mathrm{O}$ (804.97): C 93.40, H 4.65; found: C 93.57, H 4.57.

Supporting Information (see footnote on the first page of this article): Copies of ${ }^{1} \mathrm{H}$ and ${ }^{13} \mathrm{C}$ NMR, UV/Vis spectra and continuous change in the visible spectra of the reported compounds.

\section{Acknowledgments}

This work was partially supported by a Grant-in-Aid for Research Activity Start-up (Grant No. 22850007 to T.S.) from the Ministry of Education, Culture, Sports, Science and Technology, Japan.

[1] a) S. Eisler, R. R. Tykwinski, Angew. Chem. Int. Ed. 1999, 38, 1940-1943; b) F. Diederich, Pure Appl. Chem. 1999, 71, 265-273; c) Y. Zhao, R. R. Tykwinski, J. Am. Chem. Soc. 1999, 121, 458-459; d) F. Diederich, Chem. Commun. 2001, 219-227; e) H. Hopf, J. Kampen, P. Bubenitschek, P. G. Jones, Eur. J. Org. Chem. 2002, 1708-1721; f) M. Nielsen, F. Diederich, Synlett 2002, 544-552; g) K. Campbell, C. A. Johnson II, R. McDonald, M. J. Ferguson, M. M. Haley, R. R. Tykwinski, Angew. Chem. Int. Ed. 2004, 43, 5967-5971; h) M. Kivala, F. Diederich, Acc. Chem. Res. 2009, 42, 235-248.

[2] a) L. Eshdat, H. Berger, H. Hopf, M. Rabinovitz, J. Am. Chem. Soc. 2002, 124, 3822-3823; b) H. C. Shen, J. M. Tang, H. K. Chang, C. W. Yang, R. S. Liu, J. Org. Chem. 2005, 70, 10113-10116; c) N. Treitel, L. Eshdat, T. Sheradsky, P. M. Donovan, R. R. Tykwinski, L. T. Scott, H. Hopf, M. Rabinovitz, J. Am. Chem. Soc. 2006, 128 , 4703-4709; d) A. Bandyopadhyay, B. Varghese, H. Hopf, S. Sankararaman, Chem. Eur. J. 2007, 13, 3813-3821; e) F. Bureš, W. B. Schweizer, C. Boudon, J. Gisselbrecht, M. Gross, F. Diederich, Eur. J. Org. Chem. 2008, 994-1004; f) W. A. Chalifoux, R. McDonald, M. J. Ferguson, R. R. Tykwinski, Angew. Chem. Int. Ed 2009, 48, 7915-7919; g) T. Shoji, S. Ito, T. Okujima, N. Morita, Eur. J. Org. Chem. 2011, 5134-5140.

[3] G.-T. Hwang, H.-S. Son, J.-K. Ku, B.-H. Kim, J. Am. Chem. Soc. 2003, 125, 11241-11248.

[4] J. Anthony, A. M. Boldi, C. Boudon, J.-P. Gisselbrecht, M. Gross, P. Seiler, C. B. Knobler, F. Diederich, Helv. Chim. Acta 1995, 78, 797-817. 
[5] K.-P. Zeller in Methoden der Organischen Chemie (Houben-Weyl), 4th ed., Thieme, Stuttgart, 1985, vol. V, part 2c, pp. 127-418.

[6] S. Ito, H. Inabe, N. Morita, A. Tajiri, Eur. J. Org. Chem. 2004, 1774-1780.

[7] a) S. Hünig, M. Kemmer, H. Wenner, I. F. Perepichka, P. Bäuerle, A. Emge, G. Gescheidt, Chem. Eur. J. 1999, 5, 1969-1973; b) S. Hünig, M. Kemmer, H. Wenner, F. Barbosa, G. Gescheidt, I. F. Perepichka P. Bäuerle, A. Emge, K. Peters, Chem. Eur. J. 2000, 6, 2618-2632; c) S. Hünig, I. F. Perepichka, M. Kemmer, H. Wenner, P. Bäuerle, A Emge, Tetrahedron 2000, 56, 4203-4211; d) S. Hünig, C. A. Briehn, P. Bäuerle, A. Emge, Chem. Eur. J. 2001, 7, 2745-2757; e) S. Hünig, A. Langels, M. Schmittel, H. Wenner, I. F. Perepichka, K. Peters, Eur. J. Org. Chem. 2001, 1393-1399.

[8] a) S. Ito, A. Nomura, N. Morita, C. Kabuto, H. Kobayashi, S. Maejima, K. Fujimori, M. Yasunami, J. Org. Chem. 2002, 67, 7295-7302; b) S. Ito, M. Ando, A. Nomura, N. Morita, C. Kabuto, H. Mukai, K. Ohta, J. Kawakami, A. Yoshizawa, A. Tajiri, J. Org. Chem. 2005, 70, 3939-3949; c) K. Nakagawa, T. Yokoyama, K Toyota, N. Morita, S. Ito, S. Tahata, M. Ueda, J. Kawakami, M Yokoyama, Y. Kanai, K. Ohta, Tetrahedron 2010, 66, 8304-8312.

[9] a) S. Ito, S. Kikuchi, T. Okujima, N. Morita, T. Asao, J. Org. Chem. 2001, 66, 2470-2479; b) S. Ito, K. Akimoto, J. Kawakami, A. Tajiri, T. Shoji, H. Satake, N. Morita, J. Org. Chem. 2007, 72, 162-172; c) S. Ito, T. Okujima, S. Kikuchi, T. Shoji, N. Morita, T. Asao, T. Ikoma, S. Tero-Kubota, J. Kawakami, A. Tajiri, J. Org. Chem. 2008 73, 2256-2263; d) T. Shoji, J. Higashi, S. Ito, N. Morita, Eur. J. Inorg. Chem. 2010, 4886-4891; e) T. Shoji, J. Higashi, S. Ito, T. Okujima, N. Morita, Eur. J. Org. Chem. 2011, 584-592.

[10] a) T. Shoji, S. Ito, K. Toyota, M. Yasunami, N. Morita, Chem. Eur. J. 2008, 14, 8398-8408; b) T. Shoji, S. Ito, K. Toyota, T. Iwamoto, M Yasunami, N. Morita, Eur. J. Org. Chem. 2009, 4316-4324; c) T. Shoji, M. Maruyama, S. Ito, N. Morita, Bull. Chem. Soc. Jpn. 2012 85, 761-773; d) T. Shoji, S. Ito, T. Okujima, N. Morita, Org. Biomol. Chem. 2012, 10, 8308-8313.
[11] a) K. H. H. Fabian, A. H. M. Elwahy, K. Hafner, Tetrahedron Lett. 2000, 41, 2855-2858; b) K. H. H. Fabian, A. H. M. Elwahy, K. Hafner, Eur. J. Org. Chem. 2006, $791-802$.

[12] The molecular-ion peak of $\mathbf{1 1}$ was observed by HRMS spectroscopy in the crude product.

[13] Ene-diyne derivatives $\mathbf{3}, \mathbf{5}, \mathbf{8}$ and $\mathbf{1 1}$ possess solubility in chloroform, dichloromethane, toluene and ethyl acetate. However, these compounds were insoluble toward hexane, methanol and ethanol.

[14] a) S. Ito, N. Morita, Eur. J. Org. Chem. 2009, 4567-4579; b) S. Ito, T. Shoji, N. Morita, Synlett 2011, 16, 2279-2298.

[15] a) K. Komatsu, K. Ohta, T. Fujimoto, I. Yamamoto, J. Mater. Chem. 1994, 4, 533-536; b) D. R. Rosseinsky, D. M. S. Monk, J. Appl. Electrochem. 1994, 24, 1213-1221.

[16] a) S. Ito, H. Inabe, T. Okujima, N. Morita, M. Watanabe, N. Harada K. Imafukua, J. Org. Chem. 2001, 66, 7090-7101; b) S. Ito, T. Okujima, N. Morita, J. Chem. Soc., Perkin Trans. 12002, 1896-1905; c) S. Ito, H. Inabe, N. Morita, K. Ohta, T. Kitamura, K. Imafuku, J. Am. Chem. Soc. 2003, 125, 1669-1680; d) S. Ito, T. Kubo, N. Morita, T. Ikoma, S. Tero-Kubota, A. Tajiri, J. Org. Chem. 2003, 68, 9753-9762; e) S. Ito, T. Kubo, N. Morita, T. Ikoma, S Tero-Kubota, J. Kawakami, A. Tajiri, J. Org. Chem. 2005, 70 2285-2293.

[17] S. Ito, T. Iida, J. Kawakami, T. Okujima, N. Morita, Eur. J. Org. Chem. 2009, 5355-5364.

Received: ((will be filled in by the editorial staff)) Published online: ((will be filled in by the editorial staff)) 
Entry for the Table of Contents ((Please choose one layout.))

\section{Layout 1:}

Azulene Chemistry

The ene-diyne systems possessing 1and 2-azulenyl groups at the periphery, were prepared by

Sonogashira-Hagihara reaction. The redox behavior of the ene-diyne compounds was examined by cyclic voltammetry and differential pulse voltammetry. Significant color change of the ene-diyne derivatives was observed by visible spectroscopy under electrochemical reduction conditions.

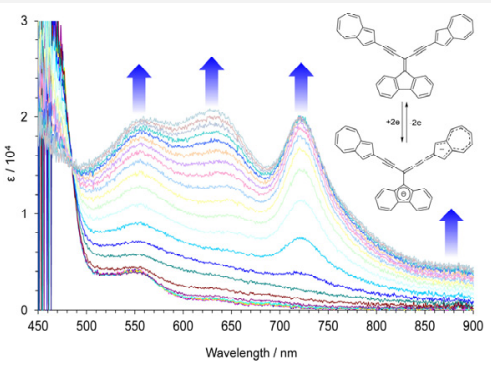

Taku Shoji,* Erika Shimomura, Mitsuhisa Maruyama, Shunji Ito, Tetsuo Okujima, Noboru Morita Page No. - Page No.

Synthesis, Properties and Redox Behavior of Ene-Diyne Scaffolds Bearing 1- and 2-Azulenyl groups at the Periphery

Keywords: Azulene / Ene-diyne / $\pi$-Conjugate system / Coupling reaction / Redox chemistry 
